Conclusions Thus, these data suggest that determination of multiple antibodies increases the diagnostic power of serological testing and may be a feasible tool for the prediction of MTX response especially in combined models.

Disclosure of interest D. Sieghart: None declared, A. Platzer: None declared, F. Alasti: None declared, P. Studenic: None declared, M. Grundhuber Employee of: Thermo Fisher Scientific - Phadia GmbH, S. Swiniarski Employee of: Thermo Fisher Scientific - Phadia GmbH, S. Blueml: None declared, T. Perkmann: None declared, J. Smolen: None declared, G. Steiner: None declared

\section{P026 BASELINE AUTOANTIBODY PROFILE IN RHEUMATOID ARTHRITIS ASSOCIATES WITH EARLY TREATMENT RESPONSE BUT NOT LONG-TERM OUTCOMES}

\footnotetext{
${ }^{1}$ EC de Moel*, ${ }^{1}$ VF Derksen, ${ }^{1}$ LA Trouw, ${ }^{2} \mathrm{H}$ Bang, ${ }^{3}$ RJ Goekoop, ${ }^{4}$ I Speyer, ${ }^{1}$ TW Huizinga, ${ }^{1}$ CF Allaart, ${ }^{1}$ RE Toes, ${ }^{1} \mathrm{D}$ van der Woude. ${ }^{1}$ Rheumatology, Leiden University Medical Centre, Leiden, Netherlands; ${ }^{2}$ Orgentec Diagnostika, Mainz, Germany; ${ }^{3}$ Rheumatology, Haga Hospital; ${ }^{4}$ Rheumatology, Haaglanden Medical Centre, The Hague, Netherlands
}

\subsection{6/annrheumdis-2018-EWRR2018.51}

Introduction The autoantibody profile of seropositive rheumatoid arthritis (RA) is very diverse and consists of various isotypes and antibodies to multiple post-translational modifications. It is yet unknown whether this varying breadth of the autoantibody profile is clinically relevant and associates with treatment outcomes.

Objectives To investigate whether the composition of the autoantibody profile in RA, as a marker of the underlying immunopathology, influences initial and long-term treatment outcomes.

Methods In sera of 399 seropositive RA patients in the IMPROVED study ${ }^{1}$ drawn at baseline and at the moment of drug tapering, we measured $\operatorname{IgG}$, IgM, and IgA isotypes for anti-cyclic citrullinated peptide- 2 and anti-carbamylated protein antibodies, IgM and IgA rheumatoid factor, and reactivity against 4 citrullinated and 2 acetylated peptides (anti-modified protein antibodies (AMPAs)). We investigated the effect of the breadth of the autoantibody profile on;

- change in disease activity score (DAS)-44 between 0 and 4 months,

- initial drug-free remission (DFR: drug-free DAS44<1.6) achieved between 1 and 2 years of follow-up, and

- long-term sustained DFR until last follow-up.

Results Corrected for age, gender, smoking, BMI, and baseline Health Assessment Questionnaire score, patients with a broad autoantibody profile at baseline had a significantly better early treatment response: $\triangle$ DAS $0-4$ months of $1-2,3-4$, and 5-6 vs 7-8 isotypes: $-1.5[\mathrm{p}<0.001],-1.7[\mathrm{p}=0.003]$, and -1.8 $[p=0.001]$ vs -2.2 . Similar results were observed for AMPAnumber; $\triangle \mathrm{DAS} 0-4$ months of $1-2,3-4$, and $5-6$ vs $7-8$ AMPAs, respectively: $-1.7[\mathrm{p}=0.016],-1.5 \quad[\mathrm{p}<0.001]$, and $-1.9[\mathrm{p}=0.22]$ vs -2.1 . However, patients with a broad baseline autoantibody profile achieved less initial DFR. For longterm sustained DFR there was no longer an association with the breadth of the autoantibody response. When assessing autoantibodies at the moment of tapering, similar results were observed.

Conclusions A broad baseline autoantibody profile is associated with a better early treatment response and a worse chance of achieving DFR at early stages, but not later in the treatment regimen, suggesting that the relevance of the autoantibody profile for treatment outcomes diminishes over time. The breadth of the baseline autoantibody profile, reflecting a break in tolerance against several different autoantigens and extensive isotype switching, may indicate a more active humoral autoimmunity which could make the underlying disease processes initially more suppressible by medication.

\section{REFERENCE}

1. Heimans. AR\&T 2016;18:23.

Disclosure of interest None declared

\section{P027 ABSTRACT WITHDRAWN}

\section{P028 TREATMENT OF BAFF TRANSGENIC MICE WITH ANTI- TNF: MONOCLONAL ANTI-TNF ARE ASSOCIATED WITH A HIGHER RISK OF LYMPHOMA THAN ETANERCEPT}

${ }^{1} \mathrm{G}$ Nocturne*, ${ }^{2} \mathrm{~B}$ Ly, ${ }^{2} \mathrm{~S}$ Boudaoud, ${ }^{2} \mathrm{~S}$ Bitoun, ${ }^{2} \mathrm{~A}$ Paoletti, ${ }^{1} \mathrm{R}$ Seror, ${ }^{3} \mathrm{C}$ Nicco, ${ }^{4} \mathrm{~F}$ Mackay, ${ }^{5} \mathrm{~F}$ Vincent, ${ }^{1} \mathrm{~S}$ Ferlicot, ${ }^{6} \mathrm{~L}$ Stimmer, ${ }^{7} \mathrm{~S}$ Roulland, ${ }^{1} \mathrm{R}$ krzysiek, ${ }^{1} \mathrm{~S}$ Hacein Bey, ${ }^{3} \mathrm{~F}$ Batteux, ${ }^{1} \mathrm{X}$ Mariette. 'Université Paris Sud; ${ }^{2}$ INSERM, Le Kremlin Bicetre; ${ }^{3}$ Paris Descartes University, Paris, France; ${ }^{4}$ Melbourne Univeristy, Melbourne; ${ }^{5}$ Monash Univeristy, Monash, Australia; ${ }^{6}$ CEA, Fontenay aux Roes; ${ }^{7}$ Marseille University, Marseille, France

\subsection{6/annrheumdis-2018-EWRR2018.52}

Introduction Risk of lymhoma in patients with rheumatoid arthritis (RA) and disease activity is the main risk factor. The impact of treatment, notably of anti-TNF, is unclear: decreasing the risk of lymphoma by controlling activity or alterring anti-tumour immunosurveillance. Anti-TNF are not associated with an increased risk of lymphoma in large epidemiologic studies. However, the risk might vary according to the type or to the dose of anti-TNF.

Objectives To assess if the risk of lymphoma might differ according to the type of anti-TNF, comparing monoclonal anti-TNF to the soluble receptor. For that, we used BAFF transgenic $(\mathrm{Tg})$ mice as a model of autoimmunity-associated lymphomas. They develop lupus and Sjögren and 3\% of them spontaneously developed lymphoma at 12-18 months.

Methods Six months aged BAFF-Tg mice were treated with antiTNF for 12 months: etanercept (ETA) ( $\mathrm{n}=15,8 \mathrm{mg} / \mathrm{kgx} 3 /$ week), monoclonal anti-mouse TNF: TN3 19.12 ( $\mathrm{n}=15,20 \mathrm{mg} / \mathrm{kg} /$ week), adalimumab (ADA) ( $\mathrm{n}=12,20 \mathrm{mg} / \mathrm{kg} /$ week) or controls $(n=22)$. Sera were assessed monthly. Crude mortality was compared among the different groups. Histological examination of the spleen was performed. The Fisher's exact test was used to compare the incidence of lymphoma among the groups.

Results Adjunction of low dose of methotrexate during the 3 first days of treatment prevented immunisation in the 3 groups for life. Using L929 cells, a cell line sensitive to TNF induced death, we confirmed that ADA was 8 to 12 times less efficient than ETA to inhibit soluble murine TNF. As expected, the mean level of ETA, TN3 and ADA were $7 \mu \mathrm{g} /$ $\mathrm{ml}, 69 \mu \mathrm{g} / \mathrm{ml}$ and $105 \mu \mathrm{g} / \mathrm{ml}$, respectively. The level of autoantibodies and serum Ig did not significantly differ among the groups. However, crude mortality was significantly higher in mice treated with monoclonal anti-TNF compared to controls $(p=0.0001$ for ADA and $p=0.0003$ for TN3) but not for mice treated with ETA. Incidence of lymphoma was higher in 
mice treated with monoclonal anti-TNF: 5/15 (33\%) with TN3 ( $p=0.03 /$ controls), 4/12 (33\%) with ADA ( $p=0.054 /$ controls), $0 / 15$ with ETA and 1/22 (5\%) in controls.

Conclusions Higher mortality and increased risk of lymphoma were observed in BAFF $\mathrm{Tg}$ mice treated with monoclonal antiTNF compared to etanercept. This result may be linked either to the different mechanism of action between the soluble receptor and the monoclonals or to a difference of trough level observed in the different groups even if higher levels of ADA was mandatory given the difference of effect on mouse TNF. This study demonstrates the negative impact of a prolonged anti-TNF treatment on the risk of lymphoma in the context of BAFF increase.

Disclosure of interest None declared

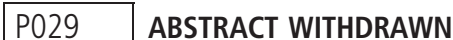

\section{P030 SERUM LEVELS OF IMMUNOGLOBULIN D AND FACTORS INFLUENCING THE LEVELS IN RHEUMATOID ARTHRITIS}

${ }^{1} \mathrm{G}$ Gravina*, ${ }^{1} \mathrm{MC}$ Erlandsson, ${ }^{2} \mathrm{~A}$ Bossios, ${ }^{2} \mathrm{~L}$ Ekerljung, ${ }^{2} \mathrm{C}$ Malmhäll, ${ }^{2} \mathrm{~B}$ Lundbäck, ${ }^{1} \mathrm{~B}$ Mikael, ${ }^{1} \mathrm{Ml}$ Bokarewa. ${ }^{1}$ Department of Rheumatology and Inflammation Research; ${ }^{2}$ Department of Internal Medicine and Clinical Nutrition, University of Gothenburg, Gothenburg, Sweden

\subsection{6/annrheumdis-2018-EWRR2018.53}

Introduction Immunoglobulin $\mathrm{D}(\mathrm{IgD})$ remains an enigmatic molecule due to the limited understanding of its function both in healthy and in patients with autoimmune diseases.

Objectives In this study we analysed serum $\operatorname{IgD}$ (sIgD) levels in patients with rheumatoid arthritis (RA) and healthy controls, paying special attention to differences related to age, gender, smoking and presence of autoantibodies

Methods sIgD levels were measured in 416 individuals: 248 (184 female, 65 male) RA patients randomly selected at Sahlgrenska and Uddevalla Hospitals, and 169 (95 female, 73 male) healthy controls selected from the OLIN epidemiological study. Sandwich ELISA was developed by using mouse monoclonal antibodies for capture and goat polyclonal for detection (both SouthernBiotech). Serum samples were tested in dilution 1:5000 and $\operatorname{sgD}$ was quantified after serial dilution of human serum with known IgD levels (Siemens, OTRD). The detection limit was $0.08 \mu \mathrm{g} / \mathrm{ml}$. Smoking information was collected from all RA patients and controls by self-reported questionnaires. ACPA and RF were measured by automatic multiplex method (anti-CCP2) and rate nephelometry technology. Statistical analysis was performed using the Mann-Whitney test.

Results Median sIgD was $38 \mu \mathrm{g} / \mathrm{ml}$ (IQR 14-97) in RA and $43 \mu \mathrm{g} / \mathrm{ml}$ (IQR 19-108) in healthy controls. sIgD was lower in RA females than RA males $(p=0.039)$ whereas healthy controls had no gender differences in sIgD. Among the females, healthy controls $<50 \mathrm{y}$ had high $\operatorname{sgD}$ compared to healthy $>50 \mathrm{y} \quad(\mathrm{p}=0.009)$, and to RA patients $<50 \mathrm{y}$ $(p=0.014)$ and $R A>50 y(p=0.046)$. $\operatorname{sgD}$ was not related to the disease activity, however, RA females producing RF alone $(p=0.009)$ and in combination with ACPA $(p=0.028)$ had low sIgD compared to non-producers. In RA, female smokers had high $\operatorname{sig} D$ compared to never $(p=0.022)$ and former smokers $(\mathrm{p}=0.003)$. Smoking was not affecting $\operatorname{sgD}$ in healthy controls. No consistent difference in $\operatorname{sgD}$ was found in males.

Conclusions The present study indicates that $\operatorname{sgD}$ is influenced by age, gender, smoking and presence of autoantibodies. Low sIgD levels seem to be pathological due to their association with RA and the presence of RF and indicate a potential link between serum $\operatorname{IgD}$ and disease severity.

Disclosure of interest None declared

\section{P031 IN BOTH RHEUMATOID AND PSORIATIC ARTHRITIS NAIVE CD4+ T LYMPHOCYTES ARE PREDISPOSED TO DIFFERENTIATE TOWARDS TH17 CELLS AND HAVE CHARACTERISTIC CYTOKINE PROFILES}

${ }^{1} \mathrm{E}$ Baricza, ${ }^{1} \mathrm{~N}$ Marton, ${ }^{1} \mathrm{P}$ Királyhidi, ${ }^{1} \mathrm{OT}$ Kovács, ${ }^{2} \mathrm{~K}$ Székely, ${ }^{1} \mathrm{E}$ Lajkó, ${ }^{1} \mathrm{~L}$ Kohidai, ${ }^{3} \mathrm{~B}$ Rojkovich, ${ }^{1} \mathrm{E}$ Barbara, ${ }^{1} \mathrm{El}$ Buzás, ${ }^{1,3} \mathrm{G}$ Nagy*. ${ }^{1}$ Department of Geneticts, Cell- and Immunolbiology, Semmelweis University; ${ }^{2}$ Budapest Business School; ${ }^{3}$ Hospital of Hospitaller Brothers of St. John of God, Budapest, Hungary

\subsection{6/annrheumdis-2018-EWRR2018.54}

Introduction The Th17 helper T lymphocytes represent a subset of $\mathrm{T}$ cells that produce inflammatory cytokines. Increased Th17 cell differentiation has been observed in rheumatoid arthritis (RA) and in psoriatic arthritis (PsA). IL-17 induced inflammation promotes osteoclast differentiation which is contributes to the bone and join destruction in RA. In addition IL-17 and IL-22 are co-expressed by Th17 cells which redounds the psoriatic plaque formation in PsA.

Objectives In this present work we studied Th17 cell differentiation in RA and PsA.

Methods Blood samples from healthy donors, RA and PsA patients were collected. $\mathrm{CD}_{45 \mathrm{RO}^{-}}$(naive) and $\mathrm{CD}_{45 \mathrm{RO}^{+}}$ (memory) $\mathrm{T}$ cells were isolated from $\mathrm{PBMC}$ by magnetic separation. Naive $\mathrm{T}$ cells were stimulated with anti-CD3, antiCD28 and with goat anti-mouse $\operatorname{IgG}$ antibodies and treated with $\mathrm{TGF}_{\beta}$, IL-6, IL- $1_{\beta}$ and IL-23 cytokines and with anti-IL-4 antibody. IL-17A and IL-22 production were measured by ELISA, RORC and TBX21 expression were analysed by qPCR and flow cytometry. CCR6, CCR4 and CXCR3 expression were determined by flow cytometry. Cell viability was monitored by impendance-based cell analyzer (CASY-TT).

Results RORC, TBX21, CCR6 and CCR4 expression of memory $\mathrm{T}$ cells of healthy individuals (but not RA or PsA patients) were increased $(\mathrm{p}<0.01 ; \mathrm{p}<0.001 ; \mathrm{p}<0.05 ; \mathrm{p}<0.05$, respectively) compared to the naive cells. Cytokine-induced IL-17A production was different in both RA and PsA patients when compared to healthy donors $(p=0.0000026$ and $p=0.0001047$, respectively). By contrast, significant differences in IL-22 production were observed only between RA versus healthy or RA versus PsA patients $(p=0.000006 ; p=0.0013454$, respectively), but not between healthy donors versus PsA patients.

Conclusions The naive CD4 T-lymphocytes are predisposed to differentiate to Th17 cells and the in vitro Th17-cell differentiation is profoundly altered in both RA and PsA.

Disclosure of interest None declared 